\title{
Prevalence and associated factors of the career plateau of primary care providers in Heilongjiang, China: a cross-sectional study
}

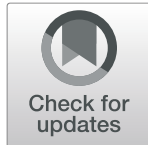

\author{
Di Liu ${ }^{1,2}$, Xu Yang ${ }^{1 *}$ D, Qinglin $\mathrm{Li}^{3}$, Lei Shi ${ }^{3}$ and Qiaoran Tang ${ }^{4}$
}

\begin{abstract}
Background: Primary care providers are pillars of China's medical and health sectors. However, due to the gap between career expectations and reality, they enter a career plateau phase through excessive pressure. This study aims to examine the prevalence and associated factors of the career plateau of primary care providers in Heilongjiang Province, China, and proposes strategies to improve and promote their career advancement.

Methods: Based on city-level GDP growth in the province, a questionnaire survey was conducted among 1500 primary care providers (effective response rate $=85.8 \%$ ). Pearson's chi-square analysis and binary logistic regression were used to analyse the factors associated with their career plateau.

Results: The prevalence rate of career plateau was $61.8 \%$ among primary care provider respondents. The factors associated with a career plateau included having a spouse $(\mathrm{OR}=1.394,95 \% \mathrm{Cl}=1.056-1.839)$, working more than $40 \mathrm{~h}$ per week $(\mathrm{OR}=1.473,95 \% \mathrm{Cl}=1.146-1.893)$; working for $11-20$ years $(\mathrm{OR}=1.607,95 \% \mathrm{Cl}=1.150-2.246)$; working for more than 20 years $(\mathrm{OR}=2.818,95 \% \mathrm{Cl}=1.938-4.097)$; having an average monthly income of 3001-4000 yuan $(\mathrm{OR}=1.886,95 \% \mathrm{Cl}=1.197-2.969)$ or $4001-5000$ yuan $(\mathrm{OR}=2.104,95 \% \mathrm{Cl}=1.256-3.524)$; and reporting unsatisfactory or very unsatisfactory sleep quality $(\mathrm{OR}=1.838,95 \% \mathrm{Cl}=1.317-2.567)$.

Conclusions: Primary care providers in Heilongjiang Province face a high career plateau, with marital status, weekly working hours, number of years employed, monthly average income, and sleep quality considered associated factors. To eliminate negative factors of the career plateau, it is necessary to provide support to primary care providers in four domains: individual, organisation, society, and policy.
\end{abstract}

Keywords: Primary care providers, Career plateau, Related factors, Path to improvement

\section{Background}

With a rapidly aging world population and increases in disease risk factors, the existing medical and health resources are increasingly less able to meet increasing demand for health services [1]. As providers of primary health services, community-level health service personnel assume multiple responsibilities of prevention,

\footnotetext{
*Correspondence: yangxu0526@126.com

'School of Economics and Management, Harbin Engineering University, Harbin, People's Republic of China

Full list of author information is available at the end of the article
}

health care, rehabilitation, health education, family planning technical services, and the diagnosis and treatment of common and frequently occurring diseases. They play an important role in the medical and health systems of various countries. Focussing on the career development of grassroots health service personnel is conducive to the improvement of their service capacity and alleviation of the contradiction between medical supply and demand [2]. In recent research on the careers of primary care providers [3-6], scholars have mainly focussed on their high sense of burnout; however, the attention paid

C C The Author(s). 2021 Open Access This article is licensed under a Creative Commons Attribution 4.0 International License, which permits use, sharing, adaptation, distribution and reproduction in any medium or format, as long as you give appropriate credit to the original author(s) and the source, provide a link to the Creative Commons licence, and indicate if changes were made. The images or other third party material in this article are included in the article's Creative Commons licence, unless indicated otherwise in a credit line to the material. If material is not included in the article's Creative Commons licence and your intended use is not permitted by statutory regulation or exceeds the permitted use, you will need to obtain permission directly from the copyright holder. To view a copy of this licence, visit http://creativecommons.org/licenses/by/4.0/ The Creative Commons Public Domain Dedication waiver (http://creativecommons.org/publicdomain/zero/1.0/) applies to the data made available in this article, unless otherwise stated in a credit line to the data. 
to their career development status, that is, career plateau, is clearly insufficient.

The concept of a career plateau was first proposed by American psychologist Ference in 1977 and can be defined as a state in which individuals have a limited possibility of future growth in their careers [7]. The career plateau marks stagnation in both the vertical and horizontal flow of jobs [8], where the possibility of individuals undertaking further responsibilities and challenges in their careers is negligible $[9,10]$. In previous studies, researchers have provided various classifications of career plateaus $[7,11-16]$. Considering the cultural adaptability of China, in this study, career plateaus can be categorised as hierarchical, content, and central plateaus. The factors associated with career plateaus are complex and varied. Feldman et al. [9] believe that the career plateau is associated with six factors: individual ability and technology, individual needs and values, pressure, internal motivation, external reward, and organisational growth. Tremblay et al. [17] indicated that the career plateau of employees is primarily associated with three major factors: individual, family, and organisation. Meanwhile, Zhang et al. [18] indicated that factors such as top-level design, institutional management, and individual attribution were responsible for the career plateau of workers. In most studies [19-22], it is stated that gender, professional title, educational background, age, working years, working time, and marital status are related factors of career plateau. It is believed that the emergence of a career plateau is related to work performance, organisational commitment, turnover intention, and job satisfaction among employees [2325 ], not only triggering psychological and physiological health issues in employees but also reducing organisational management efficiency and work performance, resulting in a loss of organisational talent $[26,27]$.

Research on the career plateau of medical and health workers [21, 22, 28-30] has mainly focussed on nurses, doctors, and other groups, with little attention to primary care providers. Only a few Chinese scholars have carried out research on such care providers. According to the research of Zhang et al. [18], the career plateau of primary care providers is particularly noticeable. In China, primary care providers (referring to health care providers in urban and rural basic medical and health institutions, specifically urban community health service centres/stands in towns and townships and rural health centres/institutions) are the mainstay of the medical and health fields, supporting the heavy medical task and contributing significantly towards China's health and economic development. In the prevention and control of COVID 19 virus, four million primary care providers in China were observed to be fighting the disease on the front line. They not only face such problems as scarce medical resources and difficult working conditions to secure career development [18, 31], but also situations where leading hospitals siphon patients, causing a shortage of patients. Moreover, China's primary-level health service institutions are short of funds and resources, with minimal external repair opportunities and insufficient talent training [18]. Further, in terms of institutional management, there is a lack of mechanisms and management [18]. In Chinese society, there is poor recognition of primary care providers [31], inadequate social respect and support, and strained doctor-patient relationships [32]. Under the new medical reform policy, the contract service of family doctors lacks incentive measures for primary care providers [3], and the extra burden without additional pay is bound to affect their enthusiasm and sense of gain [31]. Faced with the gap between career expectations and reality, primary care providers enter a career plateau phase due to excessive pressure [32].

A career plateau hinders career advancement and affects the ability to serve the public and ensure the satisfaction of patients and their health outcomes [18]. It is imperative to consider the career plateau of primary care providers to better understand their working status, avoid the loss of basic medical talents, ease the gap between the shortage of medical supply and demand, and better serve the Healthy China 2030 Strategy $[18,19]$. However, at present, only a few researchers in China have focused on the incidence of career plateau among primary care providers. This study aims to fill this gap and examine the career plateau prevalence rate and associated factors among primary care providers. The knowledge obtained from the study can be used to promote their career development, and provide a theoretical reference for the sound development of basic health care.

\section{Methods \\ Participants and procedures}

The questionnaire survey was conducted in Heilongjiang Province, China, from June to August 2019. According to the GDP of prefecture-level cities in the province, as well as the provincial statistical yearbook for 2019 [24], there are 18,460 basic medical and health institutions in Heilongjiang, including 614 county/district community health service stations, 976 township hospitals, 10,740 village clinics, and 6130 outpatient clinics. Among them, 15,007 were community primary care providers. Through stratified sampling, 1500 primary care providers from 38 community health service stations/centres in seven cities in the province were selected as study subjects. Before commencing the survey, the researchers communicated and coordinated with the research community health service centres, and after obtaining their 
consent, the questionnaire was distributed to the community health service centres. Among the 1348 questionnaires collected, those with obvious errors, incorrect answers to polygraph questions, and incomplete answers were eliminated, and a total of 1287 valid questionnaires were obtained, with an effective recovery rate of $85.8 \%$.

Inclusion criteria: staff who have been engaged in basic medical and health institutions for one year or more; and informed consent to participate in this study. Exclusion criteria: those who have been on the job for three months or more due to accumulated study, study or sick leave within one year; and security staff at primary health centres, interns, and training staff.

\section{Questionnaire}

A self-made general demographic questionnaire and the career plateau scale compiled by Baoguo Xie were employed in this study, and before the formal investigation, 50 primary care providers were selected in Harbin for a preliminary survey. According to the preliminary survey results and expert opinions, the questionnaire items of the scale were partially modified to form the final questionnaire.

\section{Demographic characteristics}

The study adopted a self-compiled general demographic questionnaire, which comprised 10 items - gender, marital status, age, educational background, work years, monthly average income, work hours per week, flexible job system, type of personnel post allocation, and sleep quality [See Additional file 1].

\section{Career plateau scale}

The career plateau scale compiled by the Chinese scholar Baoguo Xie [12] was adopted to measure the career plateau, with a total of 16 items, including 4 positive and 12 negative items. The scale included three dimensions-central plateau (six items), content plateau (six item s), and hierarchical plateau (four items) - that have been widely used in the medical and health fields in China (such as doctors, nurses, and health technicians) $[23,24,33,34]$. A six-point Likert scale was adopted for the scale, and the positive items were assigned values according to the following: $1=$ totally disagree, $2=$ relatively disagree, $3=$ somewhat disagree, $4=$ somewhat agree, $5=$ relatively agree, $6=$ fully agree $;$ the negative items were reverse-scored when calculating the average score of the career plateau and each of the three dimensions. The higher the score, the greater the possibility of entering the career plateau. An average score was equal to or greater than 4 points was considered indicative of a career plateau. The Cronbach's alpha for this scale was 0.835 , and its KMO coefficient was 0.943 [See Additional file 1].

\section{Data analysis}

The study used IBM SPSS 20.0 for statistical analysis, with a career plateau score of 4 considered the threshold: Those scoring greater than or equal to 4 were classified as the career plateau group, and those less than 4 as the non-career plateau group. Adopting a descriptive statistical analysis method, the authors analysed and described the survey subjects' career plateau levels and the mean and standard deviation of each dimension. The chi-square test was used to compare the incidence of career plateau with different demographic information. Career plateau was the dependent variable, and gender, marital status, type of establishment, weekly working hours, number of years on the job, monthly average income, and sleep quality were treated as independent variables in multivariate binary logistic regression with 95\% confidence intervals for both tests to analyse the factors associated with the career plateau. $P<0.05$ was considered statistically significant.

\section{Results}

\section{Demographic characteristics of the respondents}

The involvement in the research of primary care providers accorded priority to women (83.6\%), those aged $31-40$ years $(34.9 \%)$, having a spouse (68.5\%), education with college degree or above (53.3\%), $40 \mathrm{~h}$ a week working time more or less $(64.5 \%)$, working for a fixed number of years-10 years or less $(54.7 \%)$, non-flexible job profiles (73.0\%), types for appointment system (37.5\%), average monthly income of 2000-3000 yuan (34.2\%), and quality of sleep (41.3\%). See Table 1 for details.

\section{Descriptive analysis of the score of career plateau}

The results showed that primary health care workers were in a career plateau state overall, with an overall plateau score of $4.07 \pm 0.77$. The centralised plateau score was the highest $(4.48 \pm 1.33)$, followed by the work content plateau $(4.46 \pm 0.85)$, while the hierarchical plateau score was the lowest $(2.97 \pm 0.92)$.

\section{Associations between different demographic variables and career plateau}

The chi-square test results showed that the career plateau prevalence rate of primary care providers was $61.8 \%$ (796/1287). Compared to the non-career plateau group, age $\left(x^{2}=177.70, p<0.001\right)$, education $\left(x^{2}=7.3, p=\right.$ $0.026)$, marital status $\left(x^{2}=28.88, p<0.001\right)$, weekly working hours $\left(\chi^{2}=4.841, p=0.028\right)$, number of years on the job $\left(x^{2}=59.385, p<0.001\right)$, sleep quality $\left(x^{2}=\right.$ 19.452, $p<0.001)$, monthly income $\left(x^{2}=32.544, p<\right.$ 0.001 ), and other aspects of the career plateau group were significantly different. See Table 1 for details. 
Table 1 career plateau chi-square of survey subjects ( $N=1287)$

\begin{tabular}{|c|c|c|c|c|c|c|}
\hline Demographic characteristics & $\mathrm{N}$ & $\%$ & $\begin{array}{l}\text { The number of people on the career } \\
\text { plateau }\end{array}$ & $\begin{array}{l}\text { Percentage of career } \\
\text { plateaus }\end{array}$ & $x^{2}$ & $\mathbf{P}$ \\
\hline \multicolumn{7}{|l|}{ Gender } \\
\hline Male & 211 & 16.4 & 140 & 66.4 & \multirow[t]{2}{*}{2.167} & \multirow[t]{2}{*}{0.141} \\
\hline Female & 1076 & 83.6 & 656 & 61.0 & & \\
\hline \multicolumn{7}{|l|}{ Age group } \\
\hline$\leqq 30$ years old & 427 & 33.2 & 158 & 37.0 & \multirow[t]{4}{*}{177.70} & \multirow[t]{4}{*}{$<0.001$} \\
\hline 31-40 years old & 449 & 34.9 & 315 & 70.2 & & \\
\hline 41-50 years old & 327 & 25.4 & 249 & 76.1 & & \\
\hline$\geqq 51$ years old & 84 & 6.5 & 74 & 88.1 & & \\
\hline \multicolumn{7}{|l|}{ Marriage status } \\
\hline Have a spouse & 882 & 68.5 & 589 & 66.8 & \multirow[t]{2}{*}{28.879} & \multirow[t]{2}{*}{$<0.001$} \\
\hline No spouse & 405 & 31.5 & 207 & 51.1 & & \\
\hline \multicolumn{7}{|l|}{ Record of formal schooling } \\
\hline High school degree or below & 173 & 13.4 & 123 & 71.1 & \multirow[t]{3}{*}{7.300} & \multirow[t]{3}{*}{0.026} \\
\hline University college & 429 & 33.3 & 261 & 60.8 & & \\
\hline University degree or above & 685 & 53.3 & 412 & 60.1 & & \\
\hline \multicolumn{7}{|l|}{ Weekly working hours } \\
\hline$\leqq 40 \mathrm{~h}$ & 830 & 64.5 & 495 & 59.6 & \multirow[t]{2}{*}{4.841} & \multirow[t]{2}{*}{0.028} \\
\hline$>40 \mathrm{~h}$ & 457 & 35.5 & 301 & 65.9 & & \\
\hline \multicolumn{7}{|l|}{ Working fixed number of year } \\
\hline$\leqq 10$ years & 704 & 54.7 & 372 & 52.8 & \multirow[t]{3}{*}{59.385} & \multirow[t]{3}{*}{$<0.001$} \\
\hline $11-20$ years & 256 & 19.9 & 172 & 67.2 & & \\
\hline$\geqq 20$ years & 327 & 25.4 & 252 & 77.1 & & \\
\hline \multicolumn{7}{|l|}{ Flexible job system } \\
\hline Yes & 348 & 27.0 & 215 & 61.8 & \multirow[t]{2}{*}{0.001} & \multirow[t]{2}{*}{0.976} \\
\hline No & 939 & 73.0 & 581 & 61.9 & & \\
\hline \multicolumn{7}{|l|}{ Type of personnel post allocation } \\
\hline Utilities staffing & 481 & 37.4 & 319 & 66.3 & \multirow[t]{3}{*}{7.963} & \multirow[t]{3}{*}{0.019} \\
\hline Appointment system & 483 & 37.5 & 294 & 60.9 & & \\
\hline $\begin{array}{l}\text { Equal pay for equal work /Temporary } \\
\text { recruit }\end{array}$ & 323 & 25.1 & 183 & 56.7 & & \\
\hline \multicolumn{7}{|l|}{ Average monthly income } \\
\hline$<2000$ yuan & 127 & 9.9 & 57 & 44.9 & \multirow[t]{5}{*}{32.544} & $<0.001$ \\
\hline 2001-3000 yuan & 440 & 34.2 & 252 & 57.3 & & \\
\hline $3001-4000$ yuan & 331 & 25.7 & 213 & 64.4 & & \\
\hline 4001-5000 yuan & 215 & 16.7 & 153 & 71.2 & & \\
\hline$>5000$ yuan & 174 & 13.5 & 121 & 69.5 & & \\
\hline Quality of sleep & & & & & & \\
\hline Very satisfied and relatively satisfied & 228 & 17.7 & 126 & 55.3 & 19.452 & $<0.001$ \\
\hline General & 531 & 41.3 & 306 & 57.6 & & \\
\hline $\begin{array}{l}\text { Relatively dissatisfied and very } \\
\text { dissatisfied }\end{array}$ & 528 & 41.0 & 364 & 68.9 & & \\
\hline
\end{tabular}




\section{Binary logistic regression analysis results}

The results of binary logistic regression (Table 2) showed that marital status, weekly working hours, number of years on the job, monthly average income, and sleep quality were the factors associated with the career plateau of primary care providers. In terms of marital status, those with a spouse had a higher chance of hitting a career plateau $(\mathrm{OR}=1.394, p<0.05)$ than primary care providers at the basic level without a spouse. There was a clear positive correlation between weekly working hours of over $40 \mathrm{~h}(\mathrm{OR}=1.473, p<0.05)$ and the career plateau; that is, the longer the weekly working hours of primary care providers, the higher the incidence of the career plateau. In terms of the number of years on the job, compared with primary care providers whose working years were $\leq 10$ years, the career plateau of those with working years ranging from 11 to 20 years $(\mathrm{OR}=$ $1.607, p<0.05)$ and $\geq 20$ years $(\mathrm{OR}=2.818, p<0.05)$ registered a higher probability. With respect to monthly average income, compared with primary care providers whose monthly average income was less than 2000 yuan, the incidence of career plateau for those with a monthly average income of 3001-4000 yuan $(\mathrm{OR}=1.886, p<0.05)$ and 4001-5000 yuan $(\mathrm{OR}=2.104, p<$ 0.05 ) was higher. In terms of sleep quality, the possibility of a career plateau for primary care providers with unsatisfactory and very unsatisfactory sleep quality $(\mathrm{OR}=1.838, p<0.05)$ was higher than for those with satisfactory and relatively satisfactory sleep quality. See Table 2 for details.

\section{Discussion}

The status quo of career plateau among primary care providers

The results showed that many primary care providers had reached a career plateau state (the mean value of

Table 2 binary logistic regression analysis

\begin{tabular}{|c|c|c|c|c|c|c|c|}
\hline Statistical variables & The assignment case & $\begin{array}{l}\text { Regression } \\
\text { coefficient }\end{array}$ & $\begin{array}{l}\text { Standard } \\
\text { error }\end{array}$ & Wals & $P$ & OR & $95 \% \mathrm{Cl}$ \\
\hline \multirow[t]{2}{*}{ Gender } & $1=$ Male & 0.184 & 0.167 & 1.215 & 0.27 & 1.202 & $\begin{array}{l}0.867- \\
1.667\end{array}$ \\
\hline & $2=$ Female & & & & & contrast & \\
\hline \multirow[t]{2}{*}{ Marriage status } & $1=$ Have a spouse & 0.332 & 0.141 & 5.507 & 0.019 & 1.394 & $\begin{array}{l}1.056- \\
1.839\end{array}$ \\
\hline & $2=$ No spouse & & & & & contrast & \\
\hline \multirow[t]{2}{*}{ Weekly working hours } & $1=\leqq 40 h$ & & & & & contrast & \\
\hline & $2=>40 h$ & 0.387 & 0.128 & 9.166 & 0.002 & 1.473 & $\begin{array}{l}1.146- \\
1.893\end{array}$ \\
\hline \multirow[t]{3}{*}{ Working fixed number of year } & $1=\leqq 10$ years & & & & & contrast & \\
\hline & $2=11-20$ years & 0.474 & 0.171 & 7.707 & 0.006 & 1.607 & $\begin{array}{l}1.150- \\
2.246\end{array}$ \\
\hline & $3=\geqq 20$ years & 1.036 & 0.191 & 29.45 & $\begin{array}{l}< \\
0.001\end{array}$ & 2.818 & $\begin{array}{l}1.938- \\
4.097\end{array}$ \\
\hline \multirow{3}{*}{$\begin{array}{l}\text { Type of personnel post } \\
\text { allocation }\end{array}$} & $1=$ Utilities staffing & & & & & contrast & \\
\hline & $2=$ Appointment system & 0.323 & 0.171 & 3.579 & 0.059 & 1.382 & $\begin{array}{l}0.988- \\
1.931\end{array}$ \\
\hline & $\begin{array}{l}3=\text { Equal pay for } \\
\text { equal } \\
\text { work/Temporary recruit }\end{array}$ & 0.297 & 0.186 & 2.551 & 0.11 & 1.345 & $\begin{array}{l}0.935- \\
1.936\end{array}$ \\
\hline \multirow[t]{5}{*}{ Average monthly income } & $1=<2000$ yuan & & & & & contrast & \\
\hline & $2=2001-3000$ yuan & 0.359 & 0.211 & 2.907 & 0.088 & 1.432 & $\begin{array}{l}0.948- \\
2.165\end{array}$ \\
\hline & $3=3001-4000$ yuan & 0.634 & 0.232 & 7.496 & 0.006 & 1.886 & $\begin{array}{l}1.197- \\
2.969\end{array}$ \\
\hline & $4=4001-5000$ yuan & 0.744 & 0.263 & 7.98 & 0.005 & 2.104 & $\begin{array}{l}1.256- \\
3.524\end{array}$ \\
\hline & $5=>5001$ yuan & 0.364 & 0.298 & 1.495 & 0.221 & 1.44 & $\begin{array}{l}0.803- \\
2.582\end{array}$ \\
\hline \multirow[t]{3}{*}{ The quality of sleep } & $1=$ Very satisfied and relatively satisfied & & & & & contrast & \\
\hline & $2=$ General & 0.131 & 0.166 & 0.618 & 0.432 & 1.14 & $\begin{array}{l}0.803- \\
2.582\end{array}$ \\
\hline & $\begin{array}{l}3=\text { Relatively dissatisfied and very } \\
\text { dissatisfied }\end{array}$ & 0.609 & 0.17 & 12.77 & $\begin{array}{l}< \\
0.001\end{array}$ & 1.838 & $\begin{array}{l}1.317- \\
2.567\end{array}$ \\
\hline
\end{tabular}


the overall plateau was $4.07 \pm 0.77$ ). These findings are consistent with previous findings [18], which may reflect factors such as relatively insufficient resources of basic medical and health institutions, lack of a management mechanism, and individual psychological disorders of primary care providers. The score for centralised plateau was the highest $(4.48 \pm 1.33)$, which may be related to the relatively few post settings in basic medical and health institutions [35] and the lack of opportunities to change positions at the current level. According to the guidance document issued by Jiangxi Province in China [35], there are few core management positions and a simple personnel structure in basic medical and health institutions, which makes it less likely for primary care providers to advance towards the organisation's centre, resulting in a centralised plateau. The work content of primary care providers is also high $(4.46 \pm 0.85)$, which may be related to the absence of basic medical technology and the lack of opportunities for further study [18]. The lowest score was $2.97 \pm 0.92$, which may be related to the relatively stable and simple staff pyramid structure in primary care providers' institutions. Post-hierarchical and hierarchical systems of basic medical and health institutions are reduced and the personnel structure is relatively stable, which makes it difficult for primary care providers to reach the level plateau.

\section{The factors associated with the career plateau of primary care providers}

The results showed that marital status, weekly working hours, number of years on the job, sleep quality, and monthly average income were all associated factors for the incidence of career plateau in primary care providers.

\section{Marital status}

The findings suggest that primary care providers with spouses faced a higher probability of facing a career plateau. This is contrary to the finding of Fu et al. [21] and may reflect the low per capita GDP in Heilongjiang Province and the inadequate salary and welfare benefits of primary care providers, who are considered medical personnel. When a primary care provider has a spouse, some of them will devote time to family life and their enthusiasm for work fades. In addition, in terms of traditional Chinese culture, primary care providers with spouses may face greater pressures of family life, such as supporting parents and raising children. Due to the distinctiveness of their work, support from the families of primary care providers may also be weakened, which may affect their ability and space for promotion to some extent.

\section{Working hours}

The results show that the likelihood of career plateau was higher for primary care providers who worked more than $40 \mathrm{~h}$ a week. Working long hours also meant that primary care providers had less time to bond with family and friends and low understanding and support from them. According to the study of $\mathrm{He}$ et al. [4], a daily working time of more than seven hours could contribute to primary care providers' job burnout. Simultaneously, other studies have found that the two dimensions (hierarchical and content) of the career plateau are significantly positively correlated with each dimension of job burnout, and the centralised plateau is significantly positively correlated with dehumanisation and low personal achievement [36]. However, the primary care providers who participated in this study had worked longer times and were more likely to suffer from job burnout [4], which affects work output and leads to a plateau state.

\section{Working life}

Research shows that the number of years on the job also contributed to primary care providers experiencing a career plateau such that the more years on the job, the higher the chance of a career plateau. This is contrary to the research results of $\mathrm{Fu}$ et al. [21], which may reflect a lack of medical resources and access to knowledge for primary care providers in Heilongjiang Province. Regarding talent training, the organisation will train newly appointed personnel who lack sufficient work experience. Under the restrictions of institutional factors and human management abilities, the more the working years, the more confused primary care providers feel about their career prospects. Gradually, they develop a tired mentality that restricts their ability for selfimprovement, reduces their chances of promotion, and makes them more likely to reach the plateau state [18].

\section{Quality of sleep}

The results show that the likelihood of career plateau was higher for primary care providers who had the poor quality of sleep because it is directly associated with their physical health, making them nervous and anxious, generating a sense of job burnout, and affecting their daily work output, and thereby making them hit a career plateau [36]. Poor sleep quality will also trigger negative emotions towards work [37], which is not conducive to communicating with patients and is more likely to result in doctor-patient disputes, making them more likely to reach a plateau state in their occupation.

\section{Monthly income}

The results show that the likelihood of career plateau was higher for primary care providers who earn an average monthly income of less than 5000 yuan. Most 
employees with an average monthly income of less than 2000 yuan are new to the job and have fewer life pressures and less burden from their families, while those with a monthly average income of 4001-5000 yuan are middle-level personnel, who face a career bottleneck and multiple pressures from family life and are prone to career plateau. Among high-level personnel whose monthly average income is more than 5000 yuan, there is limited scope for promotion, but there is also limited family pressure since most of their children have graduated, and their occupation plateau prevalence rate is thus lower than in the middle-income group.

\section{Improved path of career plateau in primary care providers}

In terms of actual management, we should take measures to improve the career plateau status of primary care providers as follows: First, at the individual level, by encouraging and guiding primary care providers [18], planning their career path [21], and helping them communicate with others and providing feedback on a regular basis [18], they can be encouraged to establish the subjective consciousness of career development, strengthen their core qualities, and establish appropriate goals to adapt to the trend of career development without boundaries [38, 39]. Second, regarding organisational features, primary-level health service institutions should reduce the working hours of primary care providers and ensure adequate sleep time. Simultaneously, basic medical and health institutions should focus on the construction of organisational culture and provide career counselling channels and psychological counselling services for employees. This will make full use of its qualities and advantages and thus attract patient resources for basic medical and health institutions. Within the organization, a broadband salary structure should be implemented, formative evaluation and social evaluation must be incorporated into the multi-performance assessment mechanism, and a post-rotation system should be implemented [21]. The training of community-level primary care providers is conducted based on post competency, which provides additional career development opportunities for employees. For primary care providers with a long working life, the organisation should give them sufficient care, encourage them to constantly learn so as to improve themselves, provide them with necessary supportive resources, and strive to improve their psychological well-being, organisational recognition, and organisational commitment of community-level primary care providers. Third, at the social level, additional attention and support should be provided to the families of primary care providers (especially dual-career families) [40], so that their work can be better supported by their families and society. Simultaneously, various media channels should be used to reshape public perception of primary care providers so as to improve their sense of gain, happiness, and career honour [41]. Fourth, from a policy perspective, the level of remuneration and treatment for primary care providers should be improved. We should implement preferential treatment policies for talent and career promotion and provide more policy support to community-level medical and health institutions that are not qualified for scientific research. Concurrently, special legislation should be introduced to protect the personal rights and interests of primary care providers to create a good medical environment for them.

\section{Limitations}

This current study has certain limitations. First, regarding the classification of the career plateau, researchers have divergent opinions. This study draws on the threedimensional career plateau scale compiled by Baoguo Xie. The results may be different in other studies and require confirmation through additional research. Second, limited by time and economic cost, this research adopted a cross-sectional research method, and no follow-up survey has been carried out on primary care providers, which should be the focus of future research. Third, because of limited resources, we carried out a survey in Heilongjiang Province of China with stratified sampling, which should be further expanded in future studies.

\section{Conclusions}

This study shows that marital status, working hours, number of years on the job, sleep quality, and average monthly income are the main factors associated with the career plateau of primary care providers. To eliminate the negative associated factors of the career plateau, we should not only provide encouragement and guidance to primary care providers, but also give them full support from the organizational, social, and policy perspectives.

Every element has both yin and yang aspects, which are in harmony with qi. While a career plateau is considered negative for employees, it also brings a period of stability. Future research should focus on the positive aspect of the career plateau, that is, what positive role a career plateau brings to employees and how to appropriately use this aspect of the career plateau to improve employees' work output.

\section{Supplementary Information}

The online version contains supplementary material available at https://doi. org/10.1186/s12875-021-01389-w.

Additional file 1. Questionnaire on career plateau prevalence and associated factors of primary health care providers. The questionnaire consists of two parts: one part is the demographic variables of primary 
health care providers, and the second part is the career plateau measurement scale of primary health care providers

\section{Abbreviations}

GDP: Gross Domestic Product; COVID-19: 2019 novel coronavirus disease

\section{Acknowledgements}

The authors wish to thank all the participants, primary health services and collaborating universities for the work on this study.

\section{Authors' contributions}

$\mathrm{DL}$ participated in the design and conception of the research, data collection, data analysis, manuscript drafting for calculation, analysis of results, and manuscript writing. $X Y$ is the corresponding authors of the article, he conceived of the study, participated in its design and coordination. QLL and LS carried out the epidemiologic investigation of this study, and assisted with the literature review and data collection. QRT participated in discussion and manuscript revision. All authors participated in the revision of the manuscript and approved the final version.

\section{Funding}

The research was not specifically funded by any public, commercial or nonprofit funding agency.

\section{Availability of data and materials}

The data set used and/or analyzed in the current study may be obtained from the corresponding author upon reasonable request.

\section{Ethics approval and consent to participate}

This study was approved by the Ethics Committee of Children's Hospital of Soochow University. This study obtained the consent of all participants and signed an informed consent form before the investigation.

\section{Consent for publication}

Not applicable.

\section{Competing interests}

The authors declare that they have no competing interests.

\section{Author details}

'School of Economics and Management, Harbin Engineering University, Harbin, People's Republic of China. ${ }^{2}$ School of Marxism, Harbin Medical University, Harbin, People's Republic of China. ${ }^{3}$ School of Health Management, Harbin Medical University, Harbin, People's Republic of China. ${ }^{4}$ Children's Hospital of Soochow University, Suzhou, People's Republic of China.

\section{Received: 4 May 2020 Accepted: 9 February 2021}

\section{Published online: 17 February 2021}

\section{References}

1. Verhagen MD, Brazel DM, Dowd JB, Kashnitsky I. Mills MC: Forecasting spatial, socioeconomic and demographic variation in COVID-19 health care demand in England and Wales. BMC Med. 2020;18:203.

2. Li H, Kong P, Yu H-N, Zhao S-C, Yuan J, Meng Q-Y. Incentive factors influencing work behavier of primary care providers in China. Chinese Journal of Health Policy. 2012;5:6-11.

3. Mao H, Liang J-M, Sang Z-X, Zhang J-J, Fu Q-P, Guan X-J, et al. Analysis of job burnout of public health workers in basic medical and health institutions. Journal of Applied Preventive Medicine. 2019;5:367-70.

4. He D-D, Luo S-C, Wang Y-H, Chen X-M. Analysis on job burnout status and its influencing factors of grassroots public health service personnel in Huaian city. Chinese Journal of Industrial Hygiene and Occupational Diseases. 2019;37:129-32

5. Hippel C, Brener L, Rose G, Hippel W. Perceived inability to help is associated with client-related burnout and negative work outcomes among community mental health workers. Health Soc Care Community. 2019;00:1-8
6. Tripathy JP, Goel S, Kumar AMV. Measuring and understanding motivation among community health workers in rural health facilities in India-a mixed method study. BMC Health Serv Res. 2016;16:366.

7. Ference T P, Stoner J A, Warren E K. Managing the Career Plateau. AMR 1977;2: 602.

8. Veiga J F. Plateaued Versus Nonplateaued Managers: Career Patterns, Attitudes, and Path Potential. AMJ.1981;24:566-78.

9. Feldman, D. C. Career Plateaus Reconsidered. JOM.1988;14:69-80.

10. Mccleese CS, Eby LT. Reactions to job content plateaus: examining role ambiguity and hierarchical plateaus as moderators. Career Dev Q. 2006;55: 64-76.

11. Ma Y, Ling W-Q, Liu Y-Z. Research progress on the phenomenon of "career plateau". Journal of Psychological Science. 2003;26:531-2.

12. Xie B-G, Long L-R, Zhao Y-J. Development of career plateau questionnaire and research on its validity and reliability. Chinese Journal of Clinical Psychology. 2008;16:344-7

13. Milliman. Causes, consequences, and moderating factors of career plateauing. California:University of Southem Callfomia;1992.

14. Joseph J. An exploratory look at the Plateauism construct. Journal of Psychology Interdisciplinary \& Applied. 1996;130:237-44.

15. JM Bardwick. The plateauing trap: how to avoid it in your career--and your life. 1986.

16. Lee PCB. Going beyond career plateau using professional plateau to account for work outcomes. J Manag Dev. 2003;22:538-51.

17. Tremblay M, Roger A. Individual, Familial, and Organizational Determinants of Career Plateau: An Empirical Study of the Determinants of Objective and Subjective Career Plateau in a Population of Canadian Managers.GROUP ORGAN MANAGE.1993:18:411-35.

18. Zhang P-C, Zhang X-D. Study on the career plateau of rural primary care providers. Chinese Rural Health Service Administration. 2017:37:130-2.

19. Liu Y-H, Shao J. The survey and analysis on the current situation and influence factors of career plateau of psychiatry department nurses. J Qilu Nurs. 2012;18:48-50

20. Wang $Y-T, X u M$. The research on the current situation and influence factors of career plateau of nurses. Electronic Journal of General Stomatology. 2019; 6:121-2.

21. Fu J-Y, Li Y-J. Career plateau of ICU nurses in Shenzhen class III grade I hospitals and its related demographic factors. J Nurs. 2014;21:5-10.

22. Jiang M-M, Guo P-P, Gao K, Lu Y-Y, Wang D-W. Study on influencing factors of doctors' occupational altitude in hospitals at all levels in shanghai. Health Economics Research. 2020;37:41-5

23. Gu J, Wang X, Li L. Research status and progress of nursing staff career plateau. Chin J Prac Nurs. 2014;30:69-71.

24. Tang $Y$, Tian J-S, Chen $\mathrm{H}$. Research in the correlation of job satisfaction, job performance and career plateau in senior health technical personnel. Chin $J$ Prac Nurs. 2014;30:22-5.

25. Hu H, Yang Z, Lou M-M, Liu D-H, Xu Y-Y. Investigating the occupation satisfaction of health practitioners in primary level organization. China Health Industry. 2015:5:166-7.

26. Wang Y-T. Study on high-level brain drain of enterprises and its countermeasures -- from the perspective of career plateau. Human resource development.2016; 000:137-8.

27. Sun $Y-M$, Yang $X-L$, Feng $X-W$. Implementation of essential public health services of primary medical and health care institutions in Chongqing. Chin Gen Prac. 2015;18:227-30.

28. Saeed AAE, Mohamed AES, El Sayed HHW. Career Plateau, Self-efficacy and Job Embeddedness as Perceivedby Staff Nurses. AM J NURS.2020; 8:170-81.

29. Kim Shin Hee, Jeong Nam Ok. Influence of career plateau on the job satisfaction and nursing competency of general hospital nurses. Korean Journal of Occupational Health Nursing.2019;28:138-47.

30. Jeonga K, Heeyoung K. Relationship between career plateau, career planning, social support, and turnover intention in nurses. J Korean Acad Nurs. 2018;24:97-106.

31. Song K-M, Meng Q-Y, Qu J-B, Sun X-J. A Review of job satisfaction of primary care providers. Chinese Primary Health Care. 2012;26:1-2.

32. Zeng W-L,Wu C-L,Zhao N,Huang F-W.Exploration of Talent Team Construction in the Hospital Based on Career Plateau Phenomenon. Hospital Management Forum.2018:35:65-7+46.

33. Jiang M-M, Gao K, Guo P-P, Lu Y-Y, Wang D-W. Surveying the status of doctors' career plateau in hospitals of shanghai and its influencing factors. Chinese Health Service Management. 2020;37:540-3. 
34. Wang M. Analysis on the career plateau and countermeasures of teaching nurses in Changchun General Hospital [MD Thesis]. Jilin:jilin University;2010.

35. Health Commission of Jiangxi Province [DB/OL].2011; http:// wwwjxhfpcgovcn/doc/2011/08/18/91714shtml. Accessed 20 February 2020.

36. Jiang $X-R$, Zhang $Y$, Liang $S$. Research on the Relationship among New Generation Employees career Plateau, Job Burnout and Turnover Intention. Productivity Research.2019;9:6-11+161.

37. Li L-Z, Wang J-Q, Zhan Y, Wang M-K, Song S-Q. Investigation on sleep quality and mental health status of clinical nurses in a grade a hospital in Shiyan city and analysis of influencing factors. Journal of Hubei University of Medicine. 2020;39:401-4.

38. Zhou C. Core literacy: the path of the college counselor career plateau. High Agr Educ. 2019;000:53-6.

39. Weir David. Careers and corporate culture: Hugh Gunz, Basil Blackwell, Oxford 1989. EMJ.1990;8:78-9.doi:https://doi.org/10.1016/0263-2373 (90)90060-j

40. Song K-M, Han Z-Y, Song Y, Dou W-J, Zhen T-M. Studying on retaining and attracting rural primary health professionals in view of discrete choice experiment. Chinese Health Service Management. 2019;36:616-9.

41. Ye M. A study on the countermeasures of college teachers' "career plateau" from the perspective of happiness -- a case study of medical college counselors. Education Teaching Forum. 2019;35:25-6.

\section{Publisher's Note}

Springer Nature remains neutral with regard to jurisdictional claims in published maps and institutional affiliations.

Ready to submit your research? Choose BMC and benefit from:

- fast, convenient online submission

- thorough peer review by experienced researchers in your field

- rapid publication on acceptance

- support for research data, including large and complex data types

- gold Open Access which fosters wider collaboration and increased citations

- maximum visibility for your research: over $100 \mathrm{M}$ website views per year

At $\mathrm{BMC}$, research is always in progress.

Learn more biomedcentral.com/submissions 